\title{
Editorial
}

\section{Prospect of ILizarov in Bangladesh}

\author{
MS Akhter
}

Ilizarov compression-distraction osteosynthesis system is an independent sector in orthopedics and traumatology has got definite history of its own development. Utilization of this method in orthopedics attracts many scientists with opportunity without considerable surgical trauma to eliminate severe congenital and acquired deformity which is connected with great regeneration. Undoubtedly facts remains that compression distraction method opens new era instead of using traditional methods of surgical interventions. In 1952, G A Ilizarov developed a principle of transosseous apparatus consisting of wires and metallic rings widely used in Soviet Union. Since then this versatile method has been used in Kurgan of Russia for the next 30 years till $1980^{1}$. In 1981 in Italian AO meeting in Bellagio, Italy, Prof Ilizarov presented three topics: 1. Treatment of open fracture, 2 . The treatments of post traumatic osteomyelitis, 3. Bone lengthening. and that was the first western conference outside Russia.

In our country this method becomes popularized in early $90^{\text {th }}$ decade. Now very limited numbers of orthopedic surgeons gathered knowledge and practice this method in their orthopedic treatments.

In our country orthopedic surgeons invariably face some terrible situations like open fracture, open fracture with bone loss, post operative or post traumatic osteomyelitis with implant in situ and chronic osteomyelitis along with low socioeconomic condition of our country. For all these cases there is no answer but Ilizarov. In some problems that have historically been refractory to standard treatments such as congenital pseudarthrosis of tibia and severe hemimelias, the Ilizarov solution should be considered primarily because of proven results. Amputation stump can be lengthened to facilitate prosthetic wear and in some cases eliminate need of prosthesis. Thin bone can be made wider both strengthening and cosmetically shaping limbs such as polio, club foot. Many tumours of bone can be managed by resecting tumor part and gap can be minimized by bone lengthening. Now it is evident that methods devised by Ilizarov cover almost all pathology of locomotor apparatus ${ }^{2}$. This method involves minimum invasive procedure with least hemorrhage and joint sparing surgery permits early mobilization and weight bearing which enhances early bony consolidation.

Dr. Md Shahin Akhter, MBBS, MS (Orthopaedics), Junior Consultant, Trauma Center, Faridpur Medical College Hospital, Faridpur.

Address of correspondence :

Dr. Md Shahin Akhter, MBBS, MS (Orthopaedics), Junior Consultant, Trauma Center, Faridpur Medical College Hospital, Faridpur. Mobile: $+88-01986830923$,

Email: shahinjodder52@gmail.com
Deviation from normality is called deformity. Deformity cannot be accepted by anyone. Prof G. A. Ilizarov has introduced an excellent technique for managing various problems of musculoskeletal system including fixed deformity. The principle behind his technique has got 4 contributions: 1) Law of tension stress (Biological law) slow and steady traction on a living tissue creates a stress that become metabolically activated which results in an increase in proliferative and biosynthetic functions, 2) Methods of corticotomy, 3) Distraction osteogenesis, 4) Myriads of fixator ${ }^{3}$.

Proper passing of Ilizarov wire, exact point of entry and exit of wires and proper placement of rings have definite role in excellent outcome. Prof. Ilizarov was always fond of saying "No surgeon is justified to do any reconstructive surgery by Ilizarov technique unless he or she has got the competent idea regarding the technique and apparatus"4. So I feel I should know the basic principle of Ilizarov technique, the hardware, proper selection of patients, save corridors of the placement of wires. Understanding of kinesiology and kinematics, anatomy and basic physiology are mandatory before attempt to master this Ilizarov technique ${ }^{5}$. Development in orthopedic surgery in the past 3 decades have indeed remarkable particularly so with regard to compression-distraction method. Reconstruction by Ilizarov technique is an art and skill, which can only be mastered by the discipline of observation and practice. Ilizarov method has now gained a strong foot hold in Bangladesh. Other techniques in orthopedics, one can learn in one or two weeks but this technique one cannot learn in a short period of time. There is no training centre or academic centre in Bangladesh from where one can learn about this method. So it is the time to establish training institute either separately or in association with big orthopedic hospital like NITOR.

\section{References :}

1. Association for the Study and Application of the Method of Ilizarov Group: on- union of the femur. In: Bianchi-Maiocchi A, Aronson J, editors. Operative principles of Ilizarov. Fracture treatment, non-union, osteomyelitis, lengthening, deformity correction. Baltimore: Williams and Wilkins; 1991.

2. Paley D. Principles of Deformity Correction. New York: SpringerVerlag Berlin Heidelberg; 2002.

3. Ilizarov GA: The principle of Ilizarov method. Bull Hosp Joint Dis Orthop Inst 1998; 48(1):1-11

4. Paley D. Problems, obstacles and complications of limb lengthening by Ilizarov technique. Clin Orthop Relat Res. 1990; 250:81-104.

5. Bari MM. A colour Atlas of Limb Lengthening, Surgical Reconstruction and Deformity Correction by Ilizarov technique. Dhaka: Genesis (Pvt) Ltd; 2013. 